\title{
PASSANDO DA DOUTRINA À PRÁTICA: EZEQUIEL CORRÊA DOS SANTOS E A FARMÁCIA NACIONAL
}

\author{
Nadja Paraense dos Santos* \\ Departamento de Química Orgânica, Instituto de Química, Universidade Federal do Rio de Janeiro, Centro de Tecnologia,
} B. A, 21949-900 Rio de Janeiro - RJ, Brasil

Recebido em 23/6/06; aceito em 9/11/06; publicado na web em 14/5/07

\begin{abstract}
FROM DOCTRINE TO PRACTICE: EZEQUIEL CORREAA DOS SANTOS AND NATIONAL PHARMACY. This article presents a sample of the activities of apothecary Ezequiel Corrêa dos Santos. He was notable not only for his professional career, but also for his political militancy, making an important contribution to the development of pharmaceutical sciences in Brazil, in the XIXth century.
\end{abstract}

Keywords: history of pharmacy in Brazil; Ezequiel Corrêa dos Santos; alkaloid.

\section{INTRODUÇÃO}

A ligação entre a Química e a Farmácia, no contexto do Brasil do século XIX, mostra-se um campo fecundo nos estudos em História das Ciências. Personagens ligados à farmácia brasileira permitem análises sobre o ensino e a prática da química ${ }^{1}$.

Hoje, com a valorização da história cultural, os pesquisadores debruçam-se cada vez mais sobre as biografias e trajetórias individuais. Há um interesse pela biografia contextualizada, não pelo indivíduo em si, mas inserido em uma sociedade de determinado período e local, bem como as ligações que este estabelece em seu meio, a rede de relações que tece, os processos de tomada de decisões e os estágios intermediários².

O estudo sobre Ezequiel Corrêa dos Santos (1801-1864), Figura 1, deve-se à importância da carreira profissional deste boticário na formação e consolidação da ciência farmacêutica no Brasil do século XIX, que pode ser verificada através de seus inflamados discursos lidos na Academia Imperial de Medicina, como membro titular da Seção de Farmácia (1836) e pela fundação da Sociedade Farmacêutica Brasileira (1851-1878?). Destacamos também a sua prática, nas suas boticas ${ }^{3}$, na produção de conhecimentos sobre medicamentos feitos com substâncias brasileiras, isolando princípios ativos de plantas, como o da casca do pau-pereira, ao qual denominou pereirina (ou geissosper-

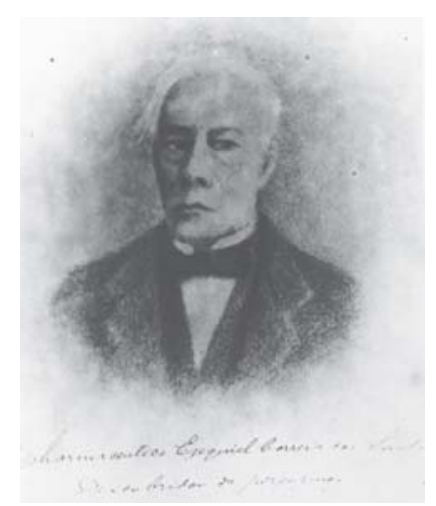

Figura 1. Retrato de Ezequiel Corrêa dos Santos, s/d. (Biblioteca Nacional, Seção de Iconografia)

*e-mail: nadja@iq.ufrj.br mina), descoberta que pode ter sido o primeiro alcalóide isolado no Brasil a partir da flora nacional ${ }^{4}$. Estes mesmos espaços eram utilizados no ensino médico-farmacêutico, voltado mais especificamente para a prática farmacêutica. Sua importante contribuição fez com que historiadores de medicina e farmácia brasileiras como Licurgo dos Santos Filho ${ }^{4}$, Messias do Carmo 5 e Coriolano de Carvalho ${ }^{6}$ o considerassem como "o mais notável farmacêutico brasileiro do século XIX", referindo-se a ele como o "pai da farmácia brasileira". Ezequiel também se destacou, em uma faceta esquecida, por sua militância política nos tempos da juventude à frente dos liberais exaltados, como panfletário político, reformista social e rebelde das ruas?.

\section{o CENÁRIO}

O século XIX já foi reconhecido por muitos autores, como aquele do entusiasmo pelo progresso alicerçado na ciência e na tecnologia. Ocorre o abandono lento e não linear da matriz artesanal dos séculos precedentes. A institucionalização e a profissionalização da ciência marcham juntas, a partir do século XVIII, respaldadas pela crescente ingerência das autoridades políticas nas atividades científicas. Como um dos resultados desse processo de transição, pode-se apontar a substituição dos práticos e boticários por farmacêuticos, que foi acompanhada simultaneamente, por mudanças no modelo de transmissão do conhecimento e de formação profissional: dos práticos e aprendizes nas boticas, passou-se à educação universitária, à organização profissional e a uma bibliografia especializada de caráter acadêmico. Foi ao longo do século XVIII e, sobretudo, no XIX que se produziu o conjunto de condições que confeririam aos farmacêuticos sua identidade específica: sistema de formação, carreira definida, título profissional e status social. Neste período surgem as especialidades farmacêuticas e dá-se início à industrialização. A farmácia deixava para trás as marcas conotadas com o empirismo da botica para passar a apresentar um aspecto intimamente relacionado com o rigor quantitativo das ciências laboratoriais. No campo da química, os avanços principalmente na área da química orgânica irão modificar os campos da terapêutica e da farmacologia. Friedrich Wöhler (1800-1882) ao sintetizar a uréia em 1828, abriu a porta à síntese laboratorial das substâncias orgânicas de importância biológica. A química acentua ainda mais a sua condição de "rival da natureza", utilizando a expressão de Diderot. A partir do século XIX isolam-se os princípios ativos vegetais. Foi marcante o início do isolamento de alcalóides que deram a partida para esta nova etapa da farmácia ${ }^{8}$. 
O Brasil acompanhou este movimento. Os primeiros boticários recebiam os ensinamentos através da prática como aprendizes. Ainda sob o domínio de Portugal, em Aviso de 23 de maio de 1800, a Real Junta do Protomedicato estabelecia os requisitos para os examinados de boticário. $\mathrm{O}$ examinado seria perguntado, executaria preparações e composições que lhes fossem solicitadas, sendo argüido por dois boticários. Ao "passar a carta", a Real Junta outorgava ao titular licença para abrir loja e vender suas preparações em qualquer lugar 9 . Com a transferência da Corte em 1808, são criados os espaços institucionais para formação de profissionais de várias áreas dentre os quais os ligados à saúde, e o ensino sistematizado das ciências, entre elas a Química. Primeiramente foram criadas a Escola de Cirurgia da Bahia (1808) e a Escola Anatômica, Cirúrgica e Médica do Rio de Janeiro (1808). Em 1813 (Rio de Janeiro) e em 1815 (Bahia), as Escolas passam a Academias Médico-Cirúrgicas, embriões das futuras Faculdades de Medicina, fundadas em 1832, onde funcionavam, além dos cursos de medicina e de cirurgia, o de parteira e o de farmácia. Em 1839, funda-se em Ouro Preto, Minas Gerais, a primeira Escola de Farmácia da América do Sul.

Em 1809, criou-se a cadeira de matéria médica e farmácia, destinada à formação dos cirurgiões. Os primeiros compêndios para uso dos alunos, publicados pela Imprensa Régia, no Rio de Janeiro, eram traduções de tratados de autores franceses. Embora a influência francesa tenha marcado amplamente o saber e as instituições médicas oficiais ao longo do período monárquico, o ambiente médico era herdeiro de uma multiplicidade de práticas, conceitos e métodos usados pelas diversas etnias que compunham o povo brasileiro.

Até 1820 eram raríssimas as especialidades farmacêuticas. A atividade era exercida nas boticas, que representavam tanto o braço "industrial" quanto o comercial do negócio. Nelas eram produzidas e vendidas as fórmulas "magistraes" e "officinaes". As primeiras eram misturas preparadas pelos boticários a partir de indicações elaboradas pelos médicos, eram porções, cozimentos, colírios, pílulas, emulsões, linimentos, cataplasmas etc. Já as segundas, eram obtidas segundo as farmacopéias, encontradas prontas nas farmácias e seu prestígio variava de acordo com a época. Eram encontradas na forma de pós, tinturas, extratos, xaropes, elixires etc., para uso nas fórmulas magistrais e para comercialização direta.

Os produtos oficinais são os precursores das especialidades farmacêuticas, as quais teriam durante muito tempo composição secreta, como forma de proteger seu "inventor", que geralmente lhes apunha o próprio nome, que passava a funcionar como marca. Alguns autores consideram que a "indústria farmacêutica brasileira nasceu dentro da botica, mais tarde transformada em farmácia" ${ }^{10}$. Os profissionais buscaram, no rastro do surgimento do curso de Farmácia (1832) e na procura de soluções para os problemas de saúde pública, principalmente o combate às febres, e do surto de modernização vivido pelo Brasil, solidificar suas ações por meio de organizações associativas profissionais, consolidando espaços de atuação, projetando a categoria nos termos da importância social do seu saber competente, na luta pela melhoria do ensino farmacêutico e pela criação de um código farmacêutico brasileiro.

\section{O PERSONAGEM}

\section{Formação}

No início do século XIX, a 10 de abril de 1801 nascia na antiga freguesia de Pilar, município de Iguaçu da Província do Rio de Janeiro, Ezequiel Corrêa dos Santos. Criou-se na Cidade do Rio de Janeiro, convertida em sede do Império Português a partir da transferência da Corte, em 1808. Este fato provocou uma série de mudanças na vida da cidade influenciando, com certeza, a formação profissional de Ezequiel. As necessidades e os problemas da cidade com a súbita chegada de cerca de 15 mil pessoas, demandaram uma rede de infra-estrutura urbana que passou a oferecer oportunidades de trabalho para as mais variadas profissões: militares, engenheiros, médicos e boticários ${ }^{11}$.

Ezequiel ingressou na Academia Médico-Cirúrgica provavelmente em 1817, após ter assistido aulas de química na Escola Militar, como previam os estatutos da instituição no período ${ }^{12}$, matriculandose no terceiro ano, findo o qual, teve de praticar por mais de um ano na botica designada pela Escola, no caso a de José Caetano de Barros (?$1841)^{13}$, onde aperfeiçoou o que aprendera com José Maria Bomtempo (1774-1843), professor de Farmácia e Matéria Médica.

O próprio Ezequiel comentou seus mais caros professores no discurso que proferiu como orador da Academia Imperial de Medicina, na sessão de 30 de junho de 1837, intitulado "Sobre a História da Farmácia no Brasil" 14 . Destacou a aula de química da Academia Real Militar, neste período conduzida pelo médico inglês Daniel Gardner (1785-1831) ${ }^{15}$, a aula de botânica no jardim do Passeio Público, da qual era professor o frei Leandro do Sacramento (1779$1829)^{16}$ e a aula de seu "respeitável mestre" o boticário português José Caetano de Barros. Ezequiel relatou que Caetano de Barros anexou em 1818 um laboratório de Farmácia ao laboratório de química do Conde da Barca ${ }^{17}$. Em pesquisa realizada na Biblioteca Nacional, encontramos uma solicitação de José Caetano de Barros ao Rei, com data anterior à de $1818^{18}$. A leitura do documento nos leva a crer que o referido laboratório era utilizado não somente para o curso de Química Prática, visando a aprovação dos boticários, mas também como laboratório de química para os alunos da Academia Médico-Cirúrgica do Rio de Janeiro e para fabricação de medicamentos para a Botica do Hospital Militar.

Aprovado nos exames finais Ezequiel foi diplomado boticário por Carta Régia datada de 2 de junho de 1819, no "Livro para registrar cartas dos facultativos, boticários e parteiras deste Município (1817-1830)"19, que se encontra no Arquivo Geral da Cidade do Rio de Janeiro. Nele pudemos verificar que Ezequiel foi examinado por José Maria Bomtempo ${ }^{20}$, aprovando-o:

“(...) assim como na Teoria como na Prática e mais modos de campos e administrador simples e compostos e mais coisas pertencentes à mesma arte (...)”.

\section{O "liberal exaltado" Ezequiel}

Casou-se com Francisca das Chagas Santos e em 7 de janeiro de 1825 nascia o filho homônimo Ezequiel Corrêa dos Santos (18251899) ${ }^{21}$, que seguiu os passos do pai e foi professor de Farmácia na Faculdade de Medicina do Rio de Janeiro. Muitos dos biógrafos de Ezequiel informam somente a existência deste filho, Ezequiel, mas encontramos em outras fontes e documentos o nome de Ernesto Frederico dos Santos. Em anúncio da "Pharmacia Ezequiel" no Almanaque Laemmert em 1870, Ernesto se apresenta:

\footnotetext{
"O abaixo assinado participa-lhes mais que tem adoptado o título de - Pharmacia Ezequiel - para o seu estabelecimento da rua do Areal n. $C$, porque muitos de seus amigos, conhecendo o estabelecimento desde o tempo de seu falecido pai o pharmaceutico Ezequiel Corrêa dos Santos, desejão honrar com sua confiança a seu único filho e sucessor"22 (grifos nossos).
}

A formação profissional de Ezequiel (pai) coincidiu com o início efetivo de sua educação política. Era um liberal convicto, com ampla penetração nos movimentos políticos, sendo o principal representante da classe dos boticários na época da Independência. As- 
sinou os autos do Fico e da Aclamação e Coroação de D. Pedro I. Em 1823, após o fechamento da Assembléia Constituinte, Ezequiel ingressou na Sociedade Secreta dos Amigos Livres onde podemos perceber dois traços característicos de sua trajetória política que o acompanharão posteriormente, quando se dedicar somente à profissão de farmacêutico: a luta pelas liberdades e o associativismo.

Nas boticas do Brasil, tanto na época colonial como na imperial, reuniam-se em determinadas horas da tarde ou da noite para discussão de natureza política ou religiosa, para conversas sobre assuntos variados, os homens de importância do lugar. Algumas boticas, como a de Ezequiel na rua das Mangueiras, eram um espaço de sociabilidade para discussão e propagação das idéias exaltadas. Daí a atualidade da quadrinha:

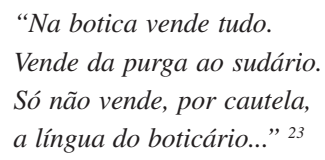

A partir de 1829 com a radicalização das lutas políticas surge na Corte uma nova facção, os liberais exaltados. Seus membros não eram integrantes da elite política ou socioeconômica do Império, sendo basicamente oriundos das camadas médias urbanas. Os exaltados fazem da imprensa seu principal canal de ação. Dentre os periódicos do período editados na Corte, encontra-se a Nova Luz Brasileira (1829-1831) ${ }^{24}$, cujo redator era Ezequiel Corrêa dos Santos. Processado em agosto de 1831 sob alegação de abuso da liberdade de imprensa, por comprometer a segurança pública ao fazer apologia ao regime republicano, foi absolvido em setembro do mesmo ano ${ }^{25}$.

Após o processo, mudou de tática e de espaço de atuação: findou a publicação da Nova Luz Brasileira e congregou seu grupo em nova associação política, fundada em dezembro de 1831, a Sociedade Federal Fluminense ${ }^{26}$, cujo principal objetivo era derrubar a Regência e proclamar o sistema federativo ou republicano.

"Ezequiel, com sua casaca de algodão da terra, seu chapéu de palha adornado com o tope nacional (o laço verde-amarelo) e uma sempre-viva na lapela; trajes tipicamente exaltados, que expressavam seus ideais de incentivo à produção nacional (...)"”.

A trajetória de "exaltado" de Ezequiel terminou com o Ato Adicional à Constituição em 12 de agosto de 1834, que consagrou a descentralização. Tornou-se membro do Partido Liberal, elegendo-se duas vezes vereador à Câmara Municipal da Corte, muito mais em função de sua ação como boticário que por suas atividades políticas.

\section{Ezequiel e as associações}

Ezequiel esteve sempre às voltas com o movimento associativo da cidade, participando ativamente, ao longo de sua vida, de diversas entidades de caráter político, como as acima citadas, mas também civis, públicas ou não. Pertenceu à Sociedade Auxiliadora da Indústria Nacional (SAIN, 1827-1904). Encontramos no Auxiliador da Indústria Nacional, periódico de divulgação da entidade, um parecer técnico de Ezequiel Corrêa dos Santos, favorável à instalação da Fábrica de São Carlos, de propriedade de Eustáquio Rodolpho de Mello Mattos, para produção de óleos vegetais ${ }^{27}$. Foi ainda sócio e presidente da Sociedade Nacional dos Artistas Brasileiros - Trabalho, União e Moralidade.

Como líder da classe dos farmacêuticos, Ezequiel participou de entidades de classe e seus discursos, lidos nas sessões públicas dessas entidades, são documentos importantes em prol do melho- ramento do ensino e da participação do farmacêutico como profissional na sociedade brasileira ${ }^{5}$. Transformada a Sociedade de Medicina do Rio de Janeiro em Academia Imperial de Medicina $(1835)^{28}$, tendo adotado uma Seção de Farmácia no dia de sua instalação, em 1836, Ezequiel Corrêa dos Santos, membro da seção, abordou a matéria do ensino farmacêutico, dando ênfase à necessidade da elaboração urgente de um Código Farmacêutico Brasilei$\mathrm{ro}^{29}$ que, pela primeira vez, contemplasse a riquíssima flora medicinal do país e a defesa do exame obrigatório dos produtos alimentícios expostos à venda. Somente com a regulamentação da Junta Central de Higiene Pública, pelo decreto $\mathrm{N}^{0} 828$ de 29 de setembro de 1851, será prevista a inspeção de "armazéns de mantimentos, casas de pasto, botequins, etc...". Neste mesmo discurso, Ezequiel propôs a criação de um curso de bacharelado prévio em Ciências Naturais e fez um histórico completo das Farmacopéias mundiais.

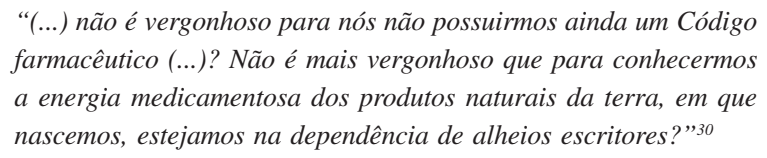
farmacêutico (...)? Não é mais vergonhoso que para conhecermos a energia medicamentosa dos produtos naturais da terra, em que nascemos, estejamos na dependência de alheios escritores?" 30

No ano seguinte (1837), Ezequiel voltou à tribuna, agora como presidente da Seção de Farmácia, e fez um longo e profundo estudo sobre a evolução da Farmácia no Brasil e no mundo. Apelou aos legisladores e ao futuro rei para que se transformasse no grande protetor da Medicina e da Farmácia $^{5}$. Mais uma vez clamava pelo estabelecimento de um código farmacêutico nacional. Em resposta, o governo decidiu adotar oficialmente o código francês de medicamentos - Codex Medicamentarius Gallicus -, que permaneceu em vigor até 1929. Ezequiel é patrono da Cadeira número 100 da Academia Nacional de Medicina.

Em 30 de março de 1851, Ezequiel Corrêa dos Santos fundou a Sociedade Farmacêutica do Rio de Janeiro (1851-1878? ${ }^{31}$ com fins de regularizar e garantir o exercício da farmácia no Brasil. Foi a primeira sociedade da classe farmacêutica no Brasil do século XIX. Ezequiel permaneceu no cargo de presidente desde a fundação até 1864, quando faleceu. Contando com o apoio do Imperador D. Pedro II e com cerca de 70 sócios, a entidade surgiu após a criação da Junta Central de Higiene em 1850, cujo Regulamento, de 29 de setembro do mesmo ano, estabelecia uma fiscalização mais eficiente dos serviços sanitários do Império. Na sessão de instalação da entidade, Ezequiel Corrêa dos Santos pronunciou no ato de sua posse, seu discurso-plataforma, onde expandiu suas idéias e seu grande programa. Em julho de 1851, começou a circular a Revista Pharmacêutica, órgão de divulgação da entidade, cujo redator-chefe era o farmacêutico e doutor Ezequiel Corrêa dos Santos (filho). Este periódico circulou de forma irregular até 1857, sendo substituído, em 1862, por novo periódico, A Abelha ${ }^{32}$.

O prof. Francisco de Paula Cândido, médico e presidente da Junta de Higiene Pública, em novembro de 1851, solicitou a colaboração da Sociedade na organização das tabelas e dos materiais que uma botica deveria conter. Ezequiel Corrêa dos Santos foi nomeado para o cargo de adjunto da Junta em 7 de julho de 1852, passando a visitar as farmácias e procurando facilitar o papel fiscalizador da autoridade sanitária. Um dos frutos da participação de Ezequiel na Junta foi o decreto de 7 de outubro de 1852, do Governo Imperial, que indicava para uso das boticas do Império, a tabela de medicamentos, as farmacopéias, os vasilhames e instrumentos adequados ${ }^{4}$. Este mesmo decreto determinava que somente os boticários e droguistas poderiam vender substâncias venenosas e que seria necessária uma autorização especial para venda de remédios de composição desconhecida. Apesar desta estreita colaboração, a Junta dispensou a colaboração dos farmacêuticos, quando a Sociedade passou a criticar a forte influência dos médicos junto ao órgão. 
A organização dos farmacêuticos não se restringiu à iniciativa de Ezequiel; em 29 de julho de 1858, Eduardo Julio Janvrot (18311892) fundou o Instituto Pharmaceutico do Rio de Janeiro (18581887), com propostas semelhantes à da Sociedade Pharmaceutica Brasileira. Segundo Lycurgo dos Santos Filho ${ }^{4}$, o Instituto teve maior importância, organizando o primeiro congresso brasileiro e latinoamericano de farmacêuticos (1877) e também pela iniciativa de fundação da Escola de Humanidades e Ciências Farmacêuticas, fundada em 1874 e que funcionou de modo irregular até 1885 .

\section{Ezequiel e o ensino de Farmácia}

Os discursos de Ezequiel repercutiram positivamente junto às autoridades. Desde seu ingresso na Academia Imperial de Medicina, não se cansou de batalhar pela melhoria do ensino de farmácia e pelo aumento dos preparatórios.

A reforma de ensino de 1832, inspirada no modelo francês, previa a criação do curso farmacêutico junto às recém-criadas faculdades de medicina do Império. $\mathrm{O}$ curso tinha a duração de 3 anos e para obter o título de farmacêutico, o aluno deveria praticar, pelo mesmo período de 3 anos, em uma botica de um boticário diplomado, durante ou após o curso.

Os farmacêuticos reivindicavam para as faculdades o monopólio da concessão dos diplomas como forma de restringir o exercício da farmácia aos homens de ciência de formação acadêmica. Na Sociedade Pharmaceutica Brasileira, Ezequiel chefiou o movimento em favor do bacharelado em Ciências Naturais para os farmacêuticos e a reforma do curso de farmácia, com a inclusão de uma cadeira prática dirigida por um farmacêutico e de disciplinas de mineralogia, zoologia e toxicologia.

Com a reforma de ensino instituída pelo Barão do Bom Retiro (Luiz Pedreira do Couto Ferraz) pelo Decreto n. ${ }^{0} 1387$ de 28 de abril de 1854, parte das reivindicações foram incorporadas ao curso farmacêutico: o estudo de mineralogia passou a ser ministrado junto com o da química e previa-se a instalação de oficinas farmacêuticas em cada faculdade, para aulas práticas. Enquanto não existissem estas oficinas, a Congregação determinaria o lugar onde se daria a prática.

Para a recém-criada cadeira de Farmácia é nomeado Manoel Maria de Moraes e Valle (1824-1866). Em 1855, a Faculdade de Medicina do Rio de Janeiro, não dispondo de salas adequadas em número suficiente, escolheu, por unanimidade dos votos da Congregação, o estabelecimento de Ezequiel para ser a escola prática de farmácia confiando-lhe a direção técnica do ensino como auxiliar. Ezequiel agradeceu a "(...) confiança que em mim e na minha botica depositou a ilustre Faculdade (...)", mas alegava que sua oficina na rua do Piolho, 113 (atual rua da Carioca) era pequena e não dispunha dos aparelhos indispensáveis. Propôs a Moraes e Valle, em carta datada de 24 de maio de $1855^{33}$ estabelecer:

“(...) um completo laboratório chimico-pharmaceutico convenientemente sortido de todos os instrumentos, aparelhos e utensis, à semelhança da Pharmacia Central de Paris dirigida pelo professor Soubeiran (...) o Governo concede ao proprietário da Pharmacia Central, como indenização (...), seu custeio de pessoal e material, o fornecimento de todas as drogas, símplices, medicamentos, compostos oficinais e magistrais que é de uso compor-se para os hospitais militares de mar e terra, etc (...)"

Ezequiel, em 24 de novembro do mesmo ano, apresentou o "Projeto para estabelecimento na Corte de um Laboratório Nacional para uma Escola Prática de Pharmacia e Chimica Médica e Industrial, servindo ao mesmo tempo de Pharmacia Central" 34 , onde explicitou de forma mais detalhada as funções do estabelecimento, solicitando além da exclusividade do fornecimento de medicamentos e drogas para os hospitais e estabelecimentos públicos a cessão de:

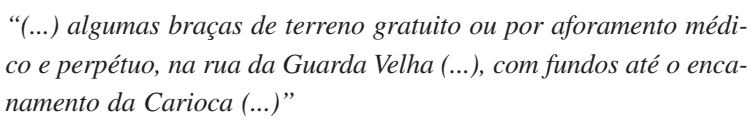
co e perpétuo, na rua da Guarda Velha (...), com fundos até o encanamento da Carioca (...)”

A proposta de Ezequiel parece ter sido aceita, pelo menos parcialmente, por volta de $1856^{35}$. Ezequiel construiu a Fábrica Nacional de Produtos Chimicos e Pharmaceuticos, na rua do Areal $n^{\circ} 4$ (atual rua Moncorvo Filho), onde seu filho homônimo lecionou aulas práticas de farmácia aos alunos da Faculdade de Medicina até 1875; somente nesta data a Faculdade de Medicina passa a ter um Laboratório de Química nas suas instalações ${ }^{36}$.

A fábrica contou com importante incentivo por parte do Governo Imperial e foi visitada por D. Pedro II, conforme registro em seu diário datado de 22 de julho de $1862^{37}$ :

\begin{abstract}
“(...) me parece bem montada, contudo já falta-lhe uma câmara ao menos para o fabrico de ácido sulfúrico. E Ezequiel disse-me que o terreno que possui não lhe chega para o estabelecimento do que é necessário para tal fabrico. Estava muito ufano com a medalha de Londres. Vi dois aparelhos engenhosos: um para preparação no vácuo com emprego de calor e outro para ter uma corrente contínua e da mesma porção de uma matéria volátil como éter, a fim de obter certas preparações."
\end{abstract}

Como se pode notar pelo comentário do Imperador, a Fábrica Nacional não funcionava somente como local para aulas práticas e manipulação de remédios para os estabelecimentos públicos, sendo também utilizado para as experiências de Ezequiel.

\section{O boticário e o cientista}

"Boticário - o que tem botica, vende drogas medicinais, e faz mezinhas. Os boticários são cozinheiros dos médicos; cozem e temperam quando nas receitas lhes ordenam" 38

No Brasil, no início da colonização o exercício da atividade farmacêutica encontrava-se nas mãos daqueles que portavam as caixas de botica ${ }^{39}$. Além dos profissionais dos estabelecimentos religiosos ou das tropas, quase não se encontravam boticários licenciados para o exercício profissional. Já no século XVIII, o Almanaque da cidade do Rio de Janeiro contabilizava 31 boticas em 1792 e 38 em 1794. Nas boticas eram encontrados remédios de origem vegetal, animal e mineral, mas somente no final do século XVIII elas passaram a comercializar medicamentos químicos de procedência européia. Muitas vezes era difícil conhecer os componentes dos medicamentos, uma vez que o segredo marcava consideravelmente a arte de curar naquele tempo. Anúncios em folhetos e jornais apregoavam as virtudes miraculosas e os preços cômodos dos remédios secretos.

Os Regimentos de Saúde exigiram que os boticários possuíssem carta de examinação ou diploma de farmacêutico, com o devido registro no Senado da Câmara. Entre 1707 e 1749, 89 boticários prestaram exames no Brasil; entre 1808 e 1821, 148 boticários foram examinados pela Fisicatura-mor. O comércio de drogas era rendoso e atraiu profissionais estrangeiros, a maioria franceses que se estabeleceram nas maiores cidades do Império.

Ezequiel, como representante de sua classe, combateu o charlatanismo que invadia o mercado brasileiro de remédios, não raro importados, anunciados publicamente nos jornais, prometen- 
do curar doenças até hoje incuráveis ${ }^{40}$. Defendendo a ética e o empirismo, Ezequiel desde 1838 passou a fazer experiências e a preparar medicamentos, utilizando principalmente a flora nativa ${ }^{41}$.

A busca de medicamento eficaz para combate ao impaludismo (malária) no Rio de Janeiro fez com que vários profissionais da área médica buscassem um princípio medicamentoso capaz de curar a terrível endemia. O catedrático de Patologia Interna da Faculdade de Medicina do Rio de Janeiro e médico do Hospital da Santa Casa, Dr. Joaquim José da Silva, começou a obter bons resultados com o emprego do decocto das cascas de pau-pereira ${ }^{42}$ nos doentes de impaludismo agudo. Ezequiel resolveu estudar este vegetal tão comum nas montanhas da Tijuca e nas Províncias da Bahia, Minas Gerais e Espírito Santo.

A árvore do pau-pereira era conhecida dos indígenas e utilizada contra impaludismo, inapetência, má digestão, tontura e prisão de ventre e como febrífugo. Além disso, sua madeira era utilizada na construção e fabricação de cabos de ferramentas agrícolas. Era empregada ainda como estimulante sexual pelos boêmios das cidades do Rio de Janeiro, de São Paulo e outras do interior.

Ezequiel tornou público, em 1838, que em 1833 havia descoberto no córtex da planta um alcalóide que denominou pereirina que, na forma de cloridrato, foi empregado largamente até princípio de século XX no combate à malária. Na tese de seu filho homônimo, em 1848, está contada a história:

\footnotetext{
"A pereirina é um alcalóide - porque goza de propriedades bazicas, e é azotada. Digo que ella goza de propriedades bazicas porque forma com os ácidos combinações estáveis; e que é azotada porque o producto de sua distillação é sensivelmente ammoniacal. Não há principio immediato algum azotado, com propriedades bazicas que não seja alcaloide" ${ }^{21}$
}

Além de Ezequiel, muitos químicos e farmacêuticos dedicaram-se ao estudo do princípio ativo das cascas do pau-pereira, fato que promove dúvida acerca da prioridade da descoberta do princípio ativo ${ }^{43}$.

Joaquim Monteiro Caminhoá (1836-1896) nos seus "Elementos de Botânica", de $1877^{44}$, menciona a descoberta de Ezequiel e diz que o pau-pereira é encontrado na composição da Água Ingle$\mathrm{sa}^{45}$. A pereirina teve sua fórmula estabelecida por Domingos José Freire Jr. (1843-1899): $\mathrm{C}_{7} \mathrm{H}_{21} \mathrm{AzO}_{10}{ }^{46}$. A fórmula estrutural da pereirina (geissoschizohma) foi estabelecida em $1958^{47}$.

Ao que tudo indica, o que Ezequiel Correa dos Santos considerava um único alcalóide, o qual denominou pereirina, na verdade era uma mistura complexa de alcalóides ${ }^{48}$.

Em trabalho recente ${ }^{49}$ foi retomado o estudo do pau-pereira e re-isolados alguns alcalóides, um destes mostrou-se inibidor da enzima acetilcolinesterase. Os medicamentos comercializados para tratamento da doença de Alzheimer são inibidores desta enzima.

Ezequiel também é citado por sintetizar o primeiro produto orgânico no Brasil, o clorofórmio $\left(\mathrm{CHCl}_{3}\right)$, em sua oficina farmacêutica da rua do Piolho, 113 (hoje, rua da Carioca). É provável que o processo de obtenção se baseasse na destilação de cloreto de cálcio com etanol ${ }^{50}$. Parece ter sido de fabricação de Ezequiel o produto utilizado na primeira cirurgia com anestesia geral com clorofórmio, realizada pelo prof. Manuel Feliciano Pereira de Carvalho, na Santa Casa de Misericórdia do Rio de Janeiro, em 18 de fevereiro de 1848, e noticiada pelo Jornal do Commercio de 22 do mesmo mês, com base nas anotações fornecidas pelo prof. Luís da Cunha Feijó, que assistira à operação, a amputação da coxa de um rapaz de 15 anos de idade, por "tumor branco do joelho" (tuberculose $)^{51}$. É interessante destacar que o clorofórmio havia sido introduzido como anestésico, em substituição ao éter, apenas um ano antes, 1847, na Inglaterra, por James Simpson.

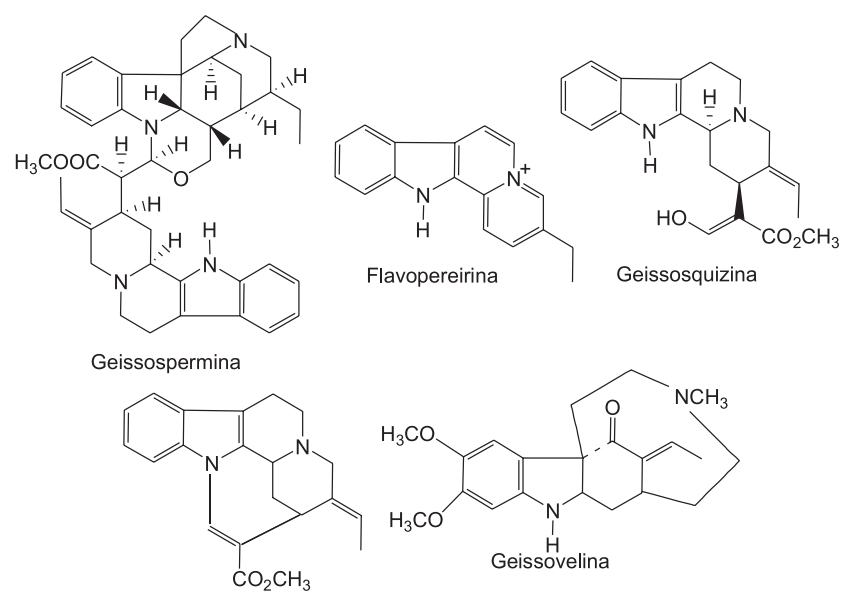

Apogeissosquizina
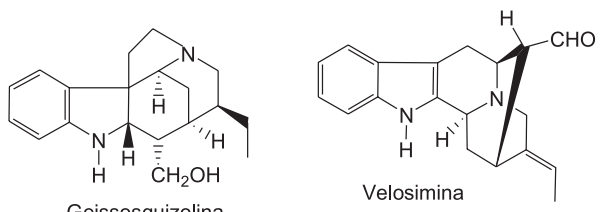

Geissosquizolina
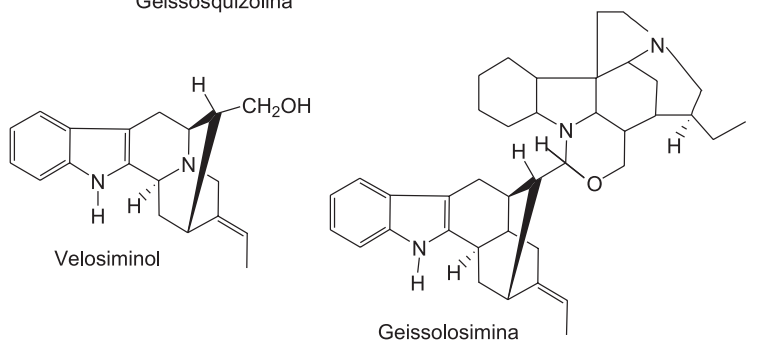

Figura 2. Alcalóides da Geissospermum vellosii

Como já mencionamos, por volta de 1856 iniciou-se o funcionamento da "Fábrica Nacional de Produtos Químicos e Farmacêuticos de Ezequiel \& Filho", que além de servir de escola prática para os alunos do curso de farmácia da Faculdade de Medicina do Rio de Janeiro produzia produtos farmacêuticos com destaque para os "Pós impalpáveis", obtidos em aparelhos especiais, "os pilões movidos a vapor e tamisados por igual movimento"; extratos aquosos e alcoólicos, já empregando a técnica "a vácuo e com emprego de vapor tão somente, quer na decocção como na evaporação"; produtos similares a determinadas especialidades estrangeiras, como o "Xarope de Saúde de Ezequiel", a "Magnésia Fluida de Ezequiel" e outros xaropes que embutiam como estratégia de venda "o propósito de destronar os que vêm do estrangeiro e que são preferidos no país só por esse fato, custando porém muito mais caro que os mesmos produtos aqui preparados" $" 52$.

Ezequiel Corrêa dos Santos participou da primeira Exposição Nacional (1861), tendo parte de seus produtos enviados à primeira Exposição Universal da qual o Brasil participaria oficialmente, a de Londres (1862). Para a sociedade imperial brasileira, a participação nas exposições universais era vista como uma espécie de vitrine de nossa civilização. Trinta e oito expositores apresentaram 519 amostras de produtos químicos e farmacêuticos. Os produtos químicos incluíam águas gasosas, cal, glicerina, barrilha, tintas, extratos, líquidos desinfetantes etc. Foram escolhidos e remetidos para a Exposição de Londres 1495 objetos, sendo 225 produtos químicos e farmacêuticos ${ }^{53}$.

Ezequiel Corrêa dos Santos apresentou uma coleção de 220 produtos, a grande maioria extraída de vegetais, entre os quais: atropina (hiosciamina), alcalóide extraído da Atropa belladona; cafeína, alcalóide extraído do café, mate, chá ou guaraná, pelo "pro- 
cesso Bonjean"; ergotina, mistura de alcalóides extraída do esporão do centeio, obtida pelo "processo Bonjean"; narcotina cristalizada; santonina cristalizada, substância com propriedade antihelmíntica extraída do gênero Artemisia; quinina, alcalóide extraído da quina na forma de acetato, arseniato, cloridrato, sulfato e valerianato; ácido valeriânico, provavelmente extraído do óleo essencial da planta do gênero Valeriana e seus derivados, valerianatos de bismuto, de ferro e de zinco.

Dos 220 produtos apresentados por Ezequiel na Exposição Nacional de 1861, somente 52 foram enviados para a Exposição Universal de Londres de 1862. Na leitura do relatório do jurado, o médico Francisco Ferreira de Abreu (1823-1885), barão de Teresópolis, podemos sublinhar críticas quanto aos processos utilizados na produção e no armazenamento, e mesmo a utilidade duvidosa de certos produtos "como fossem o racachou do Sr. Ezequiel e sua magnésia fluida, e outras imitações mais, que estão mui longe de merecer a sanção da experiência e o apoio dos homens de ciência". Ao final, o relator aproveita para ainda solicitar que Ezequiel e seu filho possam "elevar seu estabelecimento ao grau de desenvolvimento e perfeição que reclama o país", justificando o que chamou de "generoso apoio que em sua solicitude pela indústria química e farmacêutica lhes tem prodigalizado o Governo Imperial" ${ }^{54}$. Refere-se à ajuda que Ezequiel obteve para estabelecimento de sua "Fábrica Nacional de Produtos Chimicos e Pharmacêuticos".

Com a morte de Ezequiel em 1864, a administração da fábrica ficou sob a responsabilidade de seu segundo filho Ernesto. O já referido anúncio do Almanaque Laemmert de 1870 informava que o estabelecimento estava apto a preparar "todos os produtos químicos para medicina e artes", bem como "pós-impalpáveis de qualquer qualidade", "extratos a vapor evaporados a vácuo", "águas minerais gasosas", "destilações de espíritos" e "especialidades farmacêuticas diversas"

\section{EPÍLOGO}

A trajetória de Ezequiel Corrêa dos Santos nos dá uma idéia do tempo em que viveu. Primeiramente seu engajamento político nas fileiras do liberalismo, depois como farmacêutico, sua vertente de combate irá tomar outras lutas, agora pelo reconhecimento profissional, pela qualidade do ensino a ser ministrado aos farmacêuticos e pelo combate ao charlatanismo, que invadia o mercado brasileiro de remédios com panacéias e elixires. Apesar de não ser unanimidade no meio médico, não podemos deixar de destacar a descoberta da pereirina, reconhecidamente o primeiro alcalóide isolado no Brasil, cujo preparado sob a forma de cloridrato foi amplamente empregado no combate à malária até o início do século passado, constatando também que em meados do século XIX nas boticas do Rio de Janeiro se fazia química de produtos naturais.

Ezequiel destacou-se ainda no combate às epidemias de febre amarela e de cólera que assolaram a Corte em meados do século XIX, fornecendo gratuitamente medicamentos aos postos de saúde, assim como ambulâncias aos pobres e aos soldados do $4^{0}$ Batalhão de Artilharia ${ }^{6}$.

Ezequiel faleceu no dia 28 de dezembro de 1864, vítima de enterocolite, como noticiou o Diário do Rio de Janeiro, dizendo apenas que havia falecido "um químico habilitado e que era um liberal". Joaquim Manoel de Macedo $^{56}$ conta-nos que após a sua morte a Academia Imperial de Medicina fez colocar um busto de Ezequiel na sala de suas sessões públicas em homenagem ao cientista, ao historiador de sua classe, ao jornalista e ao político. Em sua homenagem foi dada a uma rua, na Cidade do Rio de Janeiro, na área do Mangue, o nome de Dr. Ezequiel, mas esta desapareceu na reurbanização da Cidade Nova.

\section{REFERÊNCIAS E NOTAS}

1. Santos, N. P.; Quim. Nova 1998, 21, 666; Santos, N. P.; História, Ciências e Saúde - Manguinhos. 2005, 12, 515.

2. Gurgel, C. B. F. M.; Anais do XI Encontro Regional de História ANPUHRIO, Rio de Janeiro, Brasil, 2004.

3. Encontramos referências a vários endereços de farmácias localizadas no centro da cidade do Rio de Janeiro que pertenceram a Ezequiel C. dos Santos. A primeira, parece ter sido localizada na R. das Mangueiras (atual R. Visconde de Maranguape), depois na R. do Conde da Cunha, 24, (atual R. Visconde do Rio Branco), R. do Piolho (atual R. da Carioca), 113 e R. do Areal (atual R. Moncorvo Filho), 4, onde funcionou a "Fábrica Nacional de Produtos Chimicos e Pharmaceuticos de Ezequiel \& Filho", Basile, M. O. N de C.; Tese de Doutorado, Universidade Federal do Rio de Janeiro, Brasil, 2000; Carrara Jr., E.; Meirelles, H.; A Indústria Química e o Desenvolvimento do Brasil - 1500-1889, Metalivros: São Paulo, 1996, tomo I, p. 299-301.

4. Santos Filho, L. de C.; História Geral da Medicina Brasileira, $2^{\mathrm{a}}$ ed., HUCITEC/EDUSP: São Paulo, 1991, vol. 2.

5. Messias do Carmo, J.; Anais do Congresso Histórico do Segundo Reinado, Rio de Janeiro, Brasil, 1975. Neste trabalho, o autor trata da evolução da farmácia no segundo reinado listando 5 discursos históricos, desses três são de Ezequiel C. dos Santos: o $1^{\circ}$ de 1836 , onde defende a necessidade de um código farmacêutico brasileiro; o $2^{\circ}$ de 1837 , sobre a evolução da farmácia brasileira e o $3^{\circ}$, de 1851 , onde traça diretrizes para uma nova era da Farmácia Brasileira.

6. Carvalho, J. C. de; Tribuna Farmacêutica, 1950, XVIII, p. 125; p. 145.

7. Basile, M. O.; Ezequiel Corrêa dos Santos, um Jacobino na Corte Imperial, Ed. FGV: Rio de Janeiro, 2001.

8. Figueirôa, S. F. M.; Vária História 2005, 21, 437. Fizemos um paralelo com o artigo, onde a autora faz um quadro da ciência e tecnologia no Brasil do século XIX, com ênfase no trabalho dos engenheiros; Santos, N. P.; Tese de Doutorado, Universidade Federal do Rio de Janeiro, Brasil, 2002.

9. Araújo, C. B. da S.; Fatos e Personagens da História da Medicina e da Farmácia no Brasil, ed. A Noite: Rio de Janeiro, 1979.

10. Rangel Filho, A. F.; Revista Brasileira de Farmácia 1957, 1-2, 25.

11. Até a chegada do Príncipe Regente D. João (1808), o aprendizado dos boticários era feito de forma prática nas boticas. O ensino de Farmácia terá início apenas em 1832. Santos Filho, L. de C., op. cit., p 332, cita uma carta régia datada de 19/8/1799, que determinava a criação, em São Paulo, de disciplinas entre as quais de "farmácia, botânica e química", mas até o momento não encontramos informações sobre a execução dessa carta.

12. Basile, M. O.; op. cit., p. 15; Carmo, J. M.; Tribuna Médica 1965, 80, 2.

13. Segundo Bandeira, J. R.; Universidade de Coimbra, Tomo II, ed. Un. Coimbra: Coimbra, 1943. José Caetano de Barros foi discípulo de Thomé Rodrigues Sobral (1759-1829), o "Chaptal português", sucessor de Domenico Vandelli na cadeira de química da Universidade de Coimbra.

14. Santos, E. C. dos; Revista Médica Fluminense 1837, 3.

15. Santos, N. P dos.; Pinto, A. C.; Alencastro, R. B. de; Quim. Nova 2000, $23,418$.

16. A partir de 1815, tiveram início no Passeio as aulas de Botânica de Frei Leandro do Sacramento, ministradas em pavilhão construído em um canto do parque. Frei Leandro mantinha seu curso regular na Academia MédicoCirúrgica, mas as aulas ao ar livre no Passeio atraíam dezenas de curiosos. Roquete-Pinto, E.; Ensaios Brasilianos, Cia Ed. Nacional: São Paulo, 1941.

17. Conde da Barca (Antônio de Araújo de Azevedo, 1754-1817). O responsável pelas atividades do laboratório era José Caetano de Barros, algumas das pesquisas realizadas nesse laboratório foram publicadas no periódico O Patriota (1813-1814); Santos, N. P.; Quim Nova 2004, 27, 342.

18. Biblioteca Nacional; Manuscritos, II-30,33,008, 4, 1817. José Caetano de Barros solicita ser nomeado professor da cadeira de Química Farmacêutica na Academia Médico-Cirúrgica do Rio de Janeiro. O pedido é negado, embora tenha a apreciação positiva de profs. da mesma Academia, como José Maria Bomtempo e Manuel Luís Álvares de Carvalho. Neste mesmo documento há um levantamento da dívida da Armada com o Laboratório de Caetano de Barros, devido ao fornecimento de medicamentos para a botica do Hospital Militar.

19. Arquivo Geral da Cidade do Rio de Janeiro; 8-3-31, "Registro da carta de Boticário Aprovado de Ezequiel Corrêa dos Santos", p. 16.

20. Por Decreto de 12/4/1809, José Maria Bomtempo foi encarregado do ensino da Medicina, Química, Matéria Médica e Farmácia. Ele foi o autor dos "Compêndios de Matéria Médica", Rio de Janeiro, Régia Oficina Tipográfica, 1814. No prefácio da obra o autor se queixava de que os alunos "não possuíam conhecimentos da química e da história natural", e na definição da área o autor diz: "Chama-se matéria médica aquela ciência que em si contém os meios de contribuir para o restabelecimento ou restauração da saúde. Fazem o objeto desta ciência, diferentes corpos dos 
três reinos da natureza, tanto no estado de símplices, como combinados por meio da química médica". O Alvará de 22/10/1810 promulgou um Regimento para os delegados do Físico-Mor. Por esse Regimento as boticas, depois de visitadas, recebiam dos Examinadores certidões nas quais constavam suas qualidades, declaradas com as letras B (boa), S (suficiente) ou R (reprovada), conforme a exatidão de seus pesos, o asseio de utensílios e vasos, a qualidade dos medicamentos. José Maria Bomtempo também instituiu um regulamento para boticários, no qual era exigido que o candidato ao ofício tivesse mais de 14 anos de idade, prática de 4 anos em botica de boticário aprovado, exame de boa educação, bons costumes, soubesse ler, escrever, contar e conhecesse a língua francesa.

21. Ezequiel Corrêa dos Santos (1825-1899) formou-se em medicina em 1848 , defendendo a tese "Monografia do geissospermum vellosii (pau-pereira)". Inicia sua carreira como professor na Faculdade de Medicina do Rio de Janeiro como Lente Substituto (professor) em 1858, passando a Lente Efetivo da Cadeira de Farmácia em 1859. Foi sócio do pai nas farmácias e na Fábrica Nacional de Produtos Chimicos e Pharmaceuticos. Foi também um dos redatores da Revista Pharmaceutica, órgão de divulgação da Sociedade Pharmaceutica Brasileira, fundada por seu pai em 1850, Blacke, A. V. A. S.; Dicionário Bibliográfico Brasileiro, Imprensa Nacional: Rio de Janeiro, 1902, vol. 2, p. 316.

22. Almanak Administrativo, Mercantil e Industrial do Rio de Janeiro [Almanaque Laemmert], 1870, notabilidades; apesar de na maior parte dos documentos encontrados constar somente como filho de Ezequiel seu homônimo, Carrara Jr., E.; Meirelles, H., op. cit., p. 613 citam a existência de um segundo filho, Ernesto Frederico dos Santos, gerente da Fábrica de Produtos Chimicos e Pharmaceuticos. No documento encontrado no Arquivo do Museu Imperial (ver nota 34), o próprio Ezequiel diz que o estabelecimento será dirigido por ele e por seus filhos: "Ezequiel (...) e o Pharmaceutico Ernesto Frederico dos Santos, que a perto de dois anos se acha em Paris praticando no laboratório chimico do Dr. Pelouze (Théophile-Jules Pelouze, 1807-1867), na Pharmacia Central do Dr. Soubeiran (Eugene Soubeiran, 1797-1858) e estudando todas as fábricas e estabelecimentos que tem relação com este."

23. Edmundo, L.; $O$ Rio de Janeiro no tempo dos vice-reis (1762-1808), Senado Federal: Brasília, 2000, p. 430.

24. Nova Luz Brasileira, Typ. Lessa \& Pereira: Rio de Janeiro. Circulou de 9/ 12/1829 a 13/10/1831, com 180 números e 5 suplementos, possuindo como característica marcante a preocupação em instruir o público leitor. Fazia oposição ao principal periódico moderado da Corte, "Aurora Brasileira", redigido pelo deputado Evaristo da Veiga. Biblioteca Nacional, setor de periódicos.

25. Anônimo; Himno dedicado pelos jovens fluminenses aos ilustres redatores do Republico, Voz e Nova Luz por ocasião de sua absolvisão (sic) no Tribunal do Jury; Lessa \& Pereira: Rio de Janeiro, 1831.

26. Coriolano de Carvalho, J.; Tribuna Farmacêutica 1950, 18, 129; Basile, M. O.; op. cit., p. 79-106. Encontramos o registro da Sociedade Filantrópica Liberdade Constitucional, fundada também em 1831, presidida por outro boticário exaltado, Juvêncio Pereira Ferreira, que possuía uma botica na Praça da Constituição, hoje Praça Tiradentes (Rio de Janeiro).

27. Eram solicitados à SAIN pareceres sobre pedidos de patentes e de privilégios industriais durante o período do Império. O Auxiliador da Indústria Nacional, no registro da sessão de 23/1/1850, contém o parecer de Ezequiel: "Os óleos de rícino, empregado como purgativo, e o de nozes, inculcado para a pintura, e o de amendoim, que aí se preparam em grande escala, são muito transparentes, privados absolutamente de mucilagem e ranço".

28. A Sociedade de Medicina do Rio de Janeiro foi organizada em 1829 com o fim de reunir médicos para debater assuntos específicos sobre saúde e doenças humanas, e também para definir o papel desse grupo frente a questões de saúde pública e do exercício da medicina. A reforma de seus estatutos foi efetivada pelo Decreto Regencial de 8/5/1835, mudando seu nome para Academia Imperial de Medicina, dividida agora em três seções: medicina, cirurgia e farmácia. Neste mesmo ano ingressam na condição de membros da seção de farmácia os farmacêuticos brasileiros Ezequiel Corrêa dos Santos, Manoel Francisco Peixoto, Juvêncio Pereira Ferreira, Francisco Félix Pereira da Costa e Estevão Alves de Magalhães, sendo a sessão presidida pelo farmacêutico francês, Jean Marie Souillé. Com a instalação do regime republicano em 1889 passou a ser denominada Academia Nacional de Medicina. Dicionário Histórico-Biográfico das Ciências da Saúde no Brasil (1832-1930); Casa de Oswaldo Cruz/FIOCRUZ - http:/ www.dichistoriasaude.coc.fiocruz.br, acessada em Maio 2006.

29. A Farmacopéia Brasileira que vinha sendo reclamada desde o século XIX, teve seu projeto apresentado na Academia Nacional de Medicina em 1920, pelo farmacêutico Rodolpho Albino Dias da Silva (1889-1931). Em 1922, durante o Primeiro Congresso Brasileiro de Farmácia, mais uma vez os farmacêuticos solicitaram a elaboração de uma farmacopéia nacional. A Farmacopéia elaborada por Rodolpho Albino foi oficializada como Código
Farmacêutico Brasileiro pelo Decreto 17.590 de 4/11/1926, tornando-se obrigatória a partir de 15/8/1929.

30. Discurso sobre a necessidade de um Código Farmacêutico Brasileiro, lido na sessão pública de 30/6/1836. Publicado na Revista Médica Fluminense, 1836. Nesta mesma Revista, ainda em 1836, é publicado o "Plano de Reorganização do Curso de Farmácia das Escolas de Medicina do Rio de Janeiro, e Bahia, e criação de Escolas Provinciais em diversas Províncias do Império", apresentado pela seção de Farmácia à Academia Imperial de Medicina. O plano não foi totalmente adotado.

31. Sociedade Farmacêutica Brasileira; ref. 28.

32. Esta denominação expressava a identificação que os farmacêuticos faziam entre seu trabalho cotidiano nas boticas, sua reunião em sociedades e o trabalho coletivo das abelhas operárias que tiravam da natureza material para sustento da colméia. Os que praticavam o exercício ilegal da farmácia ou que especulavam comercialmente as drogas e remédios eram identificados como zangões-charlatães, que viviam à custa do trabalho das industriosas abelhas, Edler, F. C.; op. cit., p. 82.

33. Carta publicada na Revista da Sociedade Pharmaceutica Barsileira 1855 IV, 146.

34. Arquivo do Museu Imperial, Maço 122 Documento 6103.

35. Biblioteca Nacional, Manuscritos pasta C-75140. Encontramos nesta pasta o Ofício $\mathrm{N}^{\circ} 512$ com uma solicitação de Ezequiel Corrêa dos Santos ao inspetor das Obras Públicas da Secretaria de Estado dos Negócios do Império, datado de 25/10/1856, no qual solicita “(...) que pela natureza de seu estabelecimento e possibilidade de incêndio precisa ter dentro dele duas penas d'água que nunca se fechem (...)". O pedido é negado em 19/11/1856.

36. Santos, E. C. dos; Memória Histórica dos Acontecimentos Notáveis no anno lectivo de 1875, Tipografia Nacional: Rio de Janeiro, 1876, p.18.

37. Bediaga, B.; Diário do Imperador D. Pedro II, cd-rom, Museu Imperial: Petrópolis, 1999.

38. Bluteau, R.; Vocabulário Portuguez e Latino, Áulico, Anatômico, Architectonico, Bellico, Botânico, Cômico, Critico, Chimico, Dogmático, etc.; Real Colégio das Artes da Companhia de Jesus: Coimbra, 1712, vol. II, p. $169-170$.

39. A caixa de botica era em geral uma arca de madeira que continha um certo número de medicamentos. Foi introduzida no Brasil pelos cirurgiõesbarbeiros, aprendizes de boticários, jesuítas, visitantes.

40. Exemplo de anúncio, Jornal do Comércio de 26/5/1862: "Bálsamo homogêneo simpático, invenção e fabricação do cirurgião italiano Pedro Garbboza, morador do Rio de Janeiro, bom para feridas, úlceras cancerosas e venéreas, sarnas, erisipelas, cirros, mal-de-lázaro, reumatismo, dor ciática, gota, queimaduras, fístulas, mordedura de animais peçonhentos, lombrigas, solitárias, menstruação, dores de estômago e de ventre, etc."

41. O aparecimento de drogas industrializadas deve-se à emergência da profissão farmacêutica. Ao combinar as habilidades e competências dos boticários, botânicos e químicos, ela permitiu o avanço do conhecimento sobre as drogas. A síntese de uréia em 1828 abriu as portas para a síntese das substâncias orgânicas. A morfina, poderoso sedativo e narcótico, foi retirada do sal de ópio em 1817, por F. W. A. Sertürner (1783-1841), a quem se atribui à descoberta dos alcalóides. Seguindo o postulado de F. Mangendie (1783-1855), que pregava ser mais eficaz a droga mais pura, o farmacêutico P.-J. Pelletier (1788-1842) isolou da ipecacuanha a emetina, usada como vomitório. Da noz-vômica, o veneno convulsivo estricnina foi extraído e indicado como tônico. A partir de então, ampla série de alcalóides foi isolada: quinina (1820), atropina (1831), codeína (1832), pereirina (1833), digitalina (1844), papaverina (1848), cocaína (1858).

42. Em cada região a planta era reconhecida por um determinado nome popular: Pau-Forquilha, Pau-de-Pente, Camará-de-bilro, Camará-do-mato, Canudo amarguroso, Pinguaciba, Pereiroá, Pereiro, Ubá-açú, Tringuaaba e Chapéu-de-sol, Pio-Corrêa, M.; Dicionário de plantas úteis do Brasil e das exóticas cultivadas, Ministério da Agricultura, 1984, vol. 4.

43. No âmbito internacional a guerra pelo pioneirismo no isolamento da pereirina foi traçada por C. H. Pfaff e B. Goos, além de P. Perreti (17811864) e P.-J. Pelletier, que fizeram suas análises na Europa. No Brasil, a maior contestação partiu de J. L. A. Blanc (?-1869), farmacêutico francês residente no Rio de Janeiro, que estudou e isolou o princípio ativo do paupereira na mesma época que Ezequiel. Almeida, M.; Pinto, A.; Santos, N. P. dos; Ciência Hoje, no prelo .

44. Caminhoá, J. M.; Elementos de Botânica Geral e Médica, Typ. Nacional: Rio de Janeiro, 1877

45. A Água Inglesa ou da Inglaterra, era um vinho de quina, muito usada como tônico e antiespasmódico. Até 1888, este produto no Brasil era considerado um segredo da família de A. L. Castro, português, porém sua fórmula já fora escrita na Farmacopéia Tubalense, editada em 1760. Na Farmacopéia Brasileira de Rodopho Albino, 1929, na p. 979 a Água Inglesa tem a sua formulação registrada. Porém é mais bem explicada através de um anúncio do Laboratório Silva Araújo publicado em 1936 na Revista da Associação 
Brasileira de Farmácia: “A Água Inglesa é fórmula excelente e clássica que todos os fabricantes de produtos farmacêuticos se vêem na obrigação de preparar, apresentando-a com pequenas variantes e peculiaridades, embora contendo os mesmos componentes primordiais: a quinina, o álcool, plantas de propriedades tônicas e anti-febris. A Água Inglesa é um aperiente, febrífugo e tônico bem indicado nas doenças febris arrastadas, nas anemias e nas convalescenças de doenças infecciosas e febris." O produto é ainda hoje fabricado, sendo indicado para a lactação.

46. Freire, D.; Recueil des travaux chimiques, Imp. de Molarinho: Rio de Janeiro, 1880.

47. Rapoport, H.; Onak, T. P.; Hughes, N. A.; Reinecke, M. G.; J. Am.. Chem. Soc. 1958, 80, 1601

48. Hughes, N. A.; Rapoport, H.; J. Am.. Chem. Soc. 1958, 80, 1604; Rapoport, H.; Windgassen, R. J.; Hughes, N. A.; Onak, T. P.; J. Am. Chem. Soc. 1960 82, 4404; Rapoport, H.; Moore, R. E.; J. Org. Chem. 1962, 27, 2981; Moore, R. E.; Rapoport, H.; J. Org. Chem. 1973, 38, 215.

49. Lima, J. A.; Tese de Doutorado, Universidade Federal do Rio de Janeiro, Brasil, 2005

50. Chernoviz, L. N.; Dicionário de Medicina Popular, $5^{\mathrm{a}}$ ed., Casa do Autor: Paris, 1878.

51. Jornal do Commercio, 22 de fevereiro de 1848

52. Fábrica Nacional de Produtos Chimicos e Pharmaceuticos de Ezequiel \& Filho - prospecto e catálogo dos produtos chimicos e pharmaceuticos do
Laboratório Ezequiel \& Filho, Rio de Janeiro s/d em Carrara Jr, E.; Meirelles. H.; op. cit.

53. Relatório Geral da Exposição Nacional de 1861 e relatório dos júris especiais coligidos (...), Typ. do Diário do Rio de Janeiro: Rio de Janeiro, 1862. Foram enviados à Londres 225 produtos de cinco farmacêuticos: Coleção Theodoro Peckolt (146 produtos - medalha de ouro); Coleção de Castro e Mendes (22 produtos - medalha de cobre), Coleção Aleixo Gary (28 produtos - medalha de cobre) e Coleção Ezequiel \& Filho (52 produtos - medalha de cobre) e Coleção Alexandre Blanc (07 produtos - medalha de cobre).

54. Relatório do Júri especial do Terceiro Grupo in Relatório Geral da Exposição Nacional de 1861, op. cit., p. 407-414.

55. Encontramos no livro de Carrara Jr., E.; Meirelles, H.; op. cit., uma longa lista dos produtos da fábrica de Ezequiel, inorgânicos e orgânicos, entre os quais citamos: ácidos: bórico, bromídrico, clorídrico, fosfórico, nítrico e silícico; arseniatos: de amônio, de ferro, de potássio e de sódio; nitratos: de bário, de chumbo, de estrôncio, básico de mercúrio e de prata; sulfatos: de amônio, de bário, cúprico, de estrôncio, básico mercúrico, de potássio e de zinco; acetato de etila; ácidos: acético (obtido por fermentação), lático e tartárico; nitrocelulose (algodão-pólvora); tartaratos: duplo de antimônio e potássio, duplo férrico e de potássio, duplo de potássio e sódio e ferroso; etc.

56. Macedo, J. M. de; Suplemento do Ano Biográfico Brasileiro, Rio de Janeiro, Typ. Et Lit. do Imperial Instituto Artístico: Rio de Janeiro, 1880. 